\title{
The role of human papillomavirus type 16 and the fragile histidine triad gene in the outcome of cervical neoplastic lesions
}

\author{
G Terry', L Ho*,', P Londesborough', P Cross², A Lopes ${ }^{3}$, J Monaghan ${ }^{3}$ and J Cuzick' \\ 'Department of Epidemiology, Mathematics and Statistics, CRUK, Wolfson Institute, Queen Mary \& Westfield University, Charterhouse Square, London \\ ECIM 6BQ, UK; ' Department of Cyto-Histopathology, Gateshead Health NHS Trust, Queen Elizabeth Hospital, Sheriff Hill Gateshead NE9 6SX, UK: \\ ${ }^{3}$ Northern Gynaecological Oncology Centre, Gateshead Health NHS Trust, Queen Elizabeth Hospital, Sheriff Hill Gateshead NE9 6SX, UK
}

The presence of high-risk human papillomavirus, loss of heterozygosity on chromosome $3 p$ and fragile histidine triad gene expression were assessed as potential markers of cancer and CIN progression in 83 cervical cancers and 74 cervical intraepithelial neoplasia grade I lesions. Human papillomavirus type 16 was an indicator of vascular involvement in cancers. Loss of heterozygosity, especially in the fragile histidine triad gene intron 5, was an indicator of high-grade tumours, greater tumour depth and lymph node involvement. Abnormal fragile histidine triad gene expression was more frequent in cervical intraepithelial neoplasia grade I lesions with increased risk of disease progression.

British Journal of Cancer (2004) 9 I, 2056-2062. doi:I0.1038/sj.bjc.6602253 www.bjcancer.com

Published online 30 November 2004

(c) 2004 Cancer Research UK

Keywords: HPVI6; FHIT; cervical cancer; CINI

Cervical cancer is the second most common cancer in women worldwide and is nearly always associated with one or more of the human papillomavirus types which have been shown to carry a high oncogenic risk (HR HPV) (Munoz et al, 2003). Most HR HPV infections are transient and resolve spontaneously. High-grade lesions (cancers and cervical intraepithelial neoplasia grades 2 and $3(\mathrm{CIN} 2 / 3))$ are more likely to result from persistent infections, particularly with HPV16 and/or high viral load (Ylitalo et al, 2000). HR HPV infection represents only one of many events occurring early in the development of cervical malignancy, however, and multiple subsequent genomic and epigenomic changes are believed to be required.

Loss of heterozygosity (LOH) is an early indicator of genomic instability, which increases the risk of malignancy. In many human cancers, $\mathrm{LOH}$ is frequently observed in the short arm of chromosome 3 (3p) (Naylor et al, 1987; Hibi et al, 1992; Druck et al, 1995; Kastury et al, 1996; Li et al, 1997). For cervical neoplasia, the chromosomal region of particular interest is $3 \mathrm{p} 14.2$ because it includes two known HPV16 integration sites (Thorland et al, 2000; Corbin et al, 2002) as well as the most commonly disrupted genomic fragile site, FRA3B (Glover and Stein, 1988). This site is sensitive to environmental carcinogens (Schantz et al, 2000) and is located between intron 3 and intron 7 of a putative tumour suppressor gene, fragile histidine triad (FHIT), which has proapoptotic activity (Ji et al, 1999; Sard et al, 1999; Dumon et al, 2001; Roz et al, 2002). One HPV insertion site is located in intron 4 and the other is centromeric to the FHIT gene. The close proximity of these genetic elements permits genomic events arising from

*Correspondence: Dr L Ho; E-mail: linda.ho@cancer.org.uk Received 12 July 2004; revised 13 October 2004; accepted 18 October 2004; published online 30 November 2004 breaks and improper repair of such breaks in this region to be readily monitored.

Loss of heterozygosity in $3 p$ and reduced FHIT expression have been reported in cervical cancer and precancer lesions (Wistuba et al, 1997; Birrer et al, 1999; Chung et al, 2000; Connolly et al, 2000; Guo et al, 2001; Acevedo et al, 2002) but, because of small sample numbers or because of differences in the $3 p$ loci selected for $\mathrm{LOH}$ analysis, it is not clear if any regions of $3 p$ are consistently deleted or if reduction in FHIT protein level is dependent on these deletions. In most studies, the HR HPV genotyping was also incomplete. More importantly, the disease outcome associated with these genomic changes has not been fully investigated. An understanding of the biological significance of changes in this chromosomal region could provide additional information relevant to the outcome of cervical lesions.

In this study, we have examined 83 cervical cancers by analysis of LOH in chromosome $3 \mathrm{p}$ and by HPV genotyping to evaluate the association between these genetic elements and standard histopathological prognostic markers (histology type, histology grade, depth of tumour invasion, blood vessel involvement and lymph node involvement) indicative of progressive disease. Genetic markers with significant associations were then analysed in 74 low-grade CIN1 lesions to see if these markers could predict the progression of cervical disease.

\section{MATERIALS AND METHODS}

Archival paraffin blocks of cervical biopsies and residual cervical cells after a smear preparation were obtained from 108 unselected women (mean age 50.9 \pm 16.3 years) referred to the Queen Elizabeth Hospital, Gateshead, Tyne and Wear for cervical cancer treatment. In all, 25 cancers were excluded from the study. Out of 
these, 11 were metastases from organs other than the cervix and 14 contained no amplifiable DNA.

A total of 78 archival paraffin blocks of loop biopsies containing only CIN1 were obtained from women (mean age $33.4 \pm 9.5$ years) referred for colposcopy. Of these, 24 biopsies were from women who had been referred following a diagnostic punch biopsy showing CIN2/3. In these cases, all of the CIN2/3 lesion was presumably contained and removed in the punch biopsy since only residual CIN1 was found at all levels in the loop biopsy. These lesions are referred to as $\mathrm{CIN} 1^{*}$ in the text. Four CIN1 biopsies contained no amplifiable DNA and were excluded from the study. Data from the remaining 83 cancers and 74 CIN1 lesions are included in this report. All histology was read by a consultant histopathologist.

\section{Staining for microscopy}

In all, 10 serial $10 \mu \mathrm{m}$ sections were prepared from each paraffin block. Section 1 was stained with haematoxylin and eosin (H\&E), section 2 was stained for proliferating cell nuclear antigen (PCNA) to confirm the proliferative activity of epithelial cells, sections 3 and 6 were stained for FHIT after epitope retrieval, sections 4 and 5 were stained with methyl-green to locate the lesion prior to microdissection and section 10 in CIN1 cases was scraped and used for HPV testing. For each case, the sections stained with H\&E and PCNA were photographed and stored digitally. The diseased and normal tissues to be dissected were selected after agreement between two observers and dissected from the corresponding methyl-green-stained sections.

All paraffin-embedded sections were dewaxed with xylene and re-hydrated in graded alcohol and water. For the H\&E stain, Gill's haematoxylin and eosin Y were used. FHIT immunostaining and assessment were carried out after epitope retrieval as described previously (Terry et al, 2002), except that Napthol-AS-BI (Sigma N-2125) and Fast Red TR (Sigma F-6760) were used as substrate following the supplier's instructions (Sigma) and Mayer's haematoxylin (Sigma MSH-1) was used as a counter stain. Loss or reduction in FHIT protein expression is referred to as 'abnormal FHIT'. Proliferating cell nuclear antigen immunostaining was carried out similarly using mouse anti-PCNA antibody (clone PC10, Sigma P8825) as the first antibody, alkaline phosphataseconjugated goat antimouse IgG antibody (Sigma A3688) as the second antibody and eosin as the counter stain. The results were assessed blind.

\section{Microdissection}

Sterile double-distilled water was used throughout. Each section was dewaxed three times with DE-WAX (InnoGenex) for $5 \mathrm{~min}$ and washed with $70 \%$ ethanol. After soaking in water for $5 \mathrm{~min}$, the section was stained with methyl-green $(1 \%)$ in water for $1 \mathrm{~min}$. Excess stain was removed by washing with water and excess water was removed by gentle shaking. While the section was still moist, normal or diseased tissue was microdissected using a $25 \mathrm{G}$ needle with the help of a dissecting microscope set up inside a tissue culture hood (Figure 1A). Special care was taken to minimise contamination with stromal tissue or lymphocytes. Dissected tissue was resuspended in $20 \mu \mathrm{l}$ T/E containing Tween $20(1 \%)$ and proteinase $\mathrm{K}\left(\mathrm{PK}, 1 \mathrm{mg} \mathrm{ml}^{-1}\right)$. Digestion was carried out for $96 \mathrm{~h}$ at $55^{\circ} \mathrm{C}$ with three additions of fresh $\mathrm{PK}$ at $24 \mathrm{~h}$ intervals. PK was inactivated subsequently at $98^{\circ} \mathrm{C}$ for $10 \mathrm{~min}$.

\section{HPV genotyping}

DNA extraction from cervical cancer scrapes using $\mathrm{PK}$ and multiplexed type-specific PCR (mts-PCR) for $13 \mathrm{HR}$ HPV types were carried out as described previously (Borysiewicz et al, 1996; Terry et al, 2002).
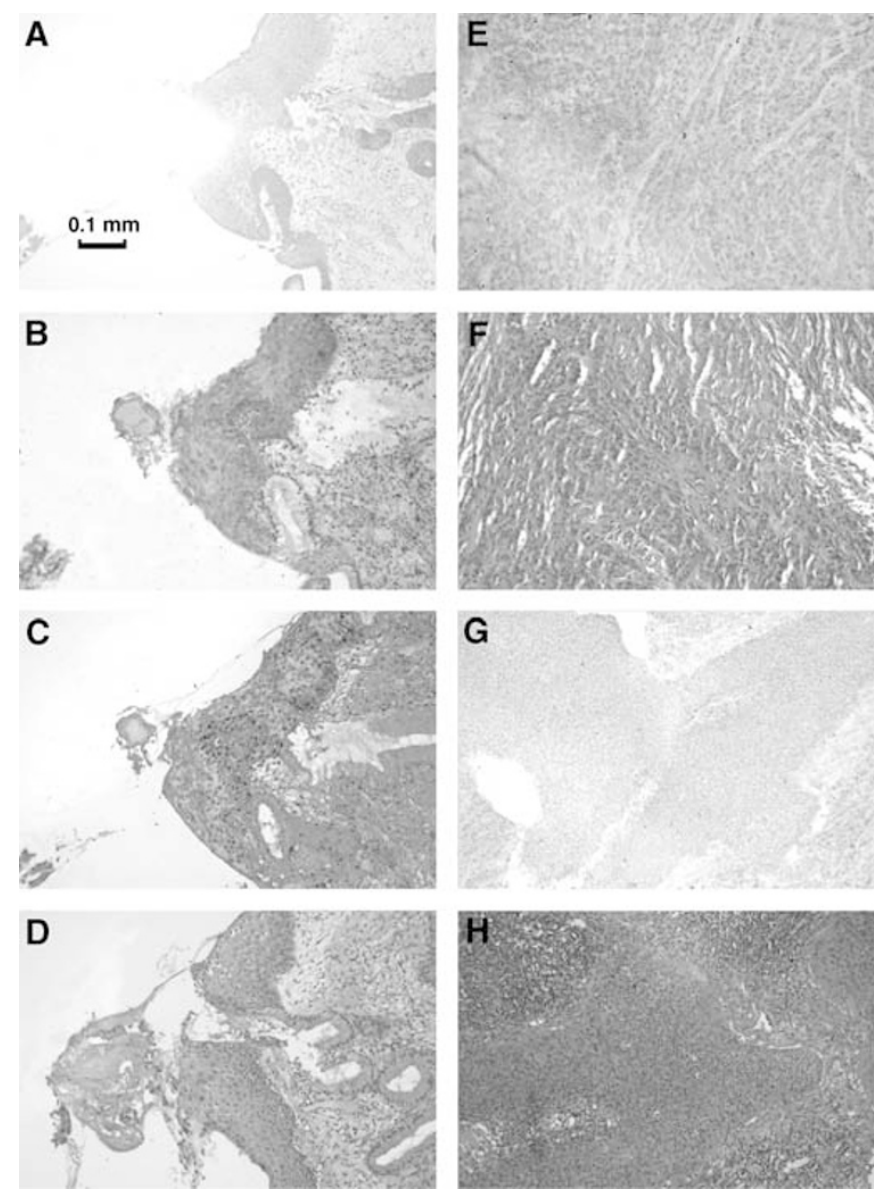

Figure I Paraffin-embedded sections of a FHIT-positive, PCNA-positive CINI lesion (A, B, C, D), a well-differentiated FHIT-positive cancer $(\mathbf{E}, \mathbf{F})$ and a poorly differentiated FHIT-negative cancer $(\mathbf{G}, \mathbf{H})$; stained with methyl green and microdissected $(\mathbf{A})$, for FHIT protein $(\mathbf{B}, \mathbf{E}, \mathbf{G})$, for PCNA (C) and with H\&E (D, F, H).

To determine HPV genotypes present in CIN1 biopsies, one section was scraped from the slide, digested with $\mathrm{PK}$ as above and amplified using the SPF primer set which can amplify a partially conserved 65 base region from at least 39 HPV types including the HR HPV types (Kleter et al, 1998). The amplicon was purified by electrophoresis on a low melting point agarose gel, followed by solubilisation of the agarose with agarase (AgarAce, Promega) and genotyping by direct sequencing (Cuzick et al, 2000) with a Cy5labelled sequencing primer.

\section{Loss of heterozygosity analysis}

Normal and cancer tissues microdissected from the same cancer section were compared. For CIN1 sections, epithelial cells from the PCNA-positive abnormal area adjacent to the squamo-columnar junction were compared with normal squamous epithelium. Two sections did not contain normal squamous epithelium and in these cases normal glandular epithelium was used as the control. Loss of heterozygosity at $303 \mathrm{p}$ loci was analysed in cancers using microsatellite (MS) or single-nucleotide polymorphism (SNP) markers. The chromosome locations of these markers are taken from the Human Genome Assembly version hg16 (July 2003). A combination of MS and SNP analyses allows LOH to be localised and validated.

Microsatellite (MS) A total of 13 MS loci were analysed in cancers (Table 1) but, since the number of cells from CIN1 lesions was 
Table I Chromosome locations of MS and SNP loci analysed on 3p and the frequency of allelic loss (FAL) in 83 cancers

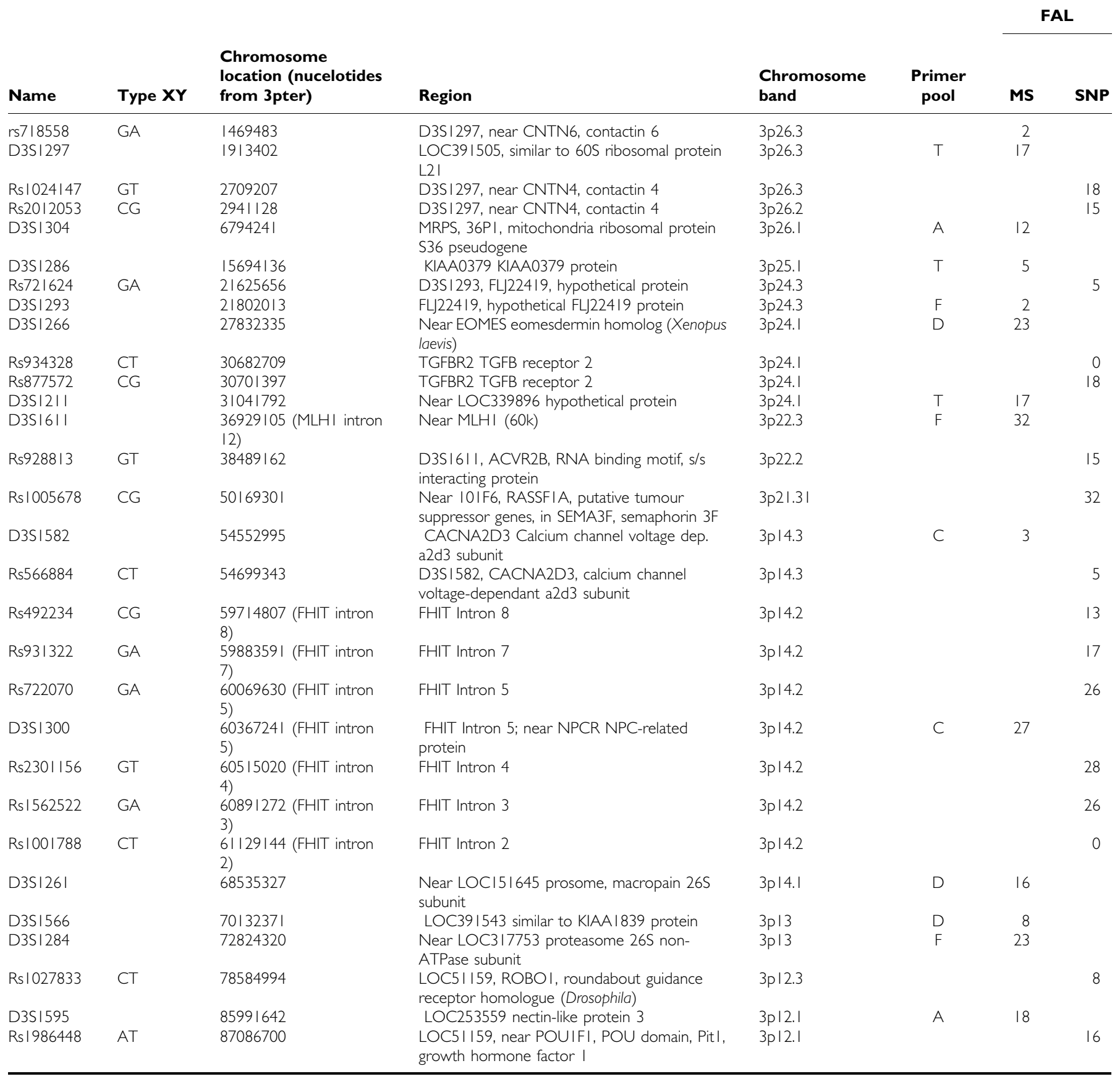

Table 2 Association of HR HPV genotypes with markers of cancer progression

\begin{tabular}{|c|c|c|c|c|c|c|}
\hline \multirow[b]{2}{*}{ HR HPV genotype } & \multirow[b]{2}{*}{ Risk marker } & \multirow[b]{2}{*}{ Grade } & \multirow[b]{2}{*}{ No. of cancers positive/total } & \multicolumn{3}{|c|}{ Statistical analysis } \\
\hline & & & & $2 P$ & OR & $95 \% \mathrm{Cl}$ \\
\hline \multirow[t]{3}{*}{16} & Origin & Squamous & $37 / 51$ & 0.022 & 3.000 & $1.074-8.388$ \\
\hline & Differentiation & Moderate & $3|/ 5|$ & 0.025 & 2.959 & $1.076-8.292$ \\
\hline & Vessel involvement & & $32 / 51$ & 0.003 & 4.304 & $1.508-12.689$ \\
\hline \multirow{2}{*}{$\begin{array}{l}\text { Group A (16+a others }) \\
18\end{array}$} & Differentiation & Moderate & $36 / 63$ & 0.042 & 3.111 & $0.954-|1.08|$ \\
\hline & Origin & Adenocarcinoma & $8 / 14$ & $<0.001$ & 10.167 & $2.316-44.760$ \\
\hline
\end{tabular}

Only significant associations are shown. ${ }^{a}$ Other types detected were HPV $31,33,52$ and 58 , all of which are members of HPV Group A. HPVI 8 is classified in Group C. 
limited ( $100-500$ cells), only two MS loci were tested in these cases, one in FHIT intron 5 (D3S1300) and the other $5 \mathrm{Mb}$ telomeric to FHIT (D3S1582). Multiplexed PCR primer pools A, C, D, F and T were used. Only pool C was used in CIN1 cases. One PCR primer for each locus was Cy5-labelled. Amplified fragments were analysed using an ALFexpress sequencer (Pharmacia Biotech) and MS peaks were quantitated using Fragment Manager software (Pharmacia Biotech). The areas under the major peaks for each MS were averaged from three independent amplifications run on different gels. Loss of heterozygosity was assigned to a cancer or CIN1 lesion, which showed an allelic ratio reduction of $\geqslant 70 \%$ relative to the corresponding normal control.

\section{Single-nucleotide polymorphisms (SNPs)}

In all, 17 SNP loci (Table 1) were amplified in cancer and normal DNA preparations from each cancer case and analysed by electrophoresis on $2 \%$ agarose gels to confirm successful amplification. Single-nucleotide polymorphism assays were carried out using SureScore Genotyping Kits according to the instructions of the manufacturer (Invitrogen). This test uses a two-channel ELISA-based assay to identify which of the two possible bases at the SNP position was added to a captured PCR amplicon in a single-base primer extension reaction. PCR primers and capture oligos for each SNP analysed were designed using the on-line software provided (Invitrogen). Each SNP experiment included 33 test samples, three allelic controls (supplied with the kit), three heterozygous and six homozygous human DNA controls and one control negative for human DNA all tested in triplicate. Loss of heterozygosity was assigned to a cancer sample when the absorbance ratio $(405 \mathrm{~nm} / 620 \mathrm{~nm})$ differed from the absorbance ratio for the corresponding normal sample by more than two standard deviations.

\section{Statistical analysis}

Association of molecular and prognostic markers was assessed using Fisher's exact test or $\chi^{2}$-test for trend. In the $\mathrm{LOH}$ analysis, the frequency of allelic loss (FAL) at a given marker was calculated as:-

total number of cancers with $\mathrm{LOH}$

total number of cancers which were informative at that locus

\section{RESULTS}

\section{Staining and immunostaining characteristics}

Figure 1 shows paraffin sections from one CIN1 lesion $(a-d)$ and two cervical cancers (e, f, g, h), stained with: methyl-green after cancer tissue had been removed by microdissection (a), FHIT antibody (b, e, g), PCNA antibody (c) and H\&E (d, f, h). Sections (b) and (e) are FHIT positive and section (g) is FHIT negative.

\section{Association with cancer prognostic markers}

HR HPV HPV16 was preferentially associated with squamous carcinoma and HPV18 with adenocarcinoma, respectively (Table 2). HPV16, but not HPV18, was associated with cancers showing moderate differentiation and vascular spread. No correlations between HR HPV status and FHIT protein expression were found. HR HPV genotypes detected other than HPV16 and HPV18 were HPV31, 33, 52 and 58. Like HPV16, these are all group A viruses and the group A viruses taken together also show an association with moderate differentiation.
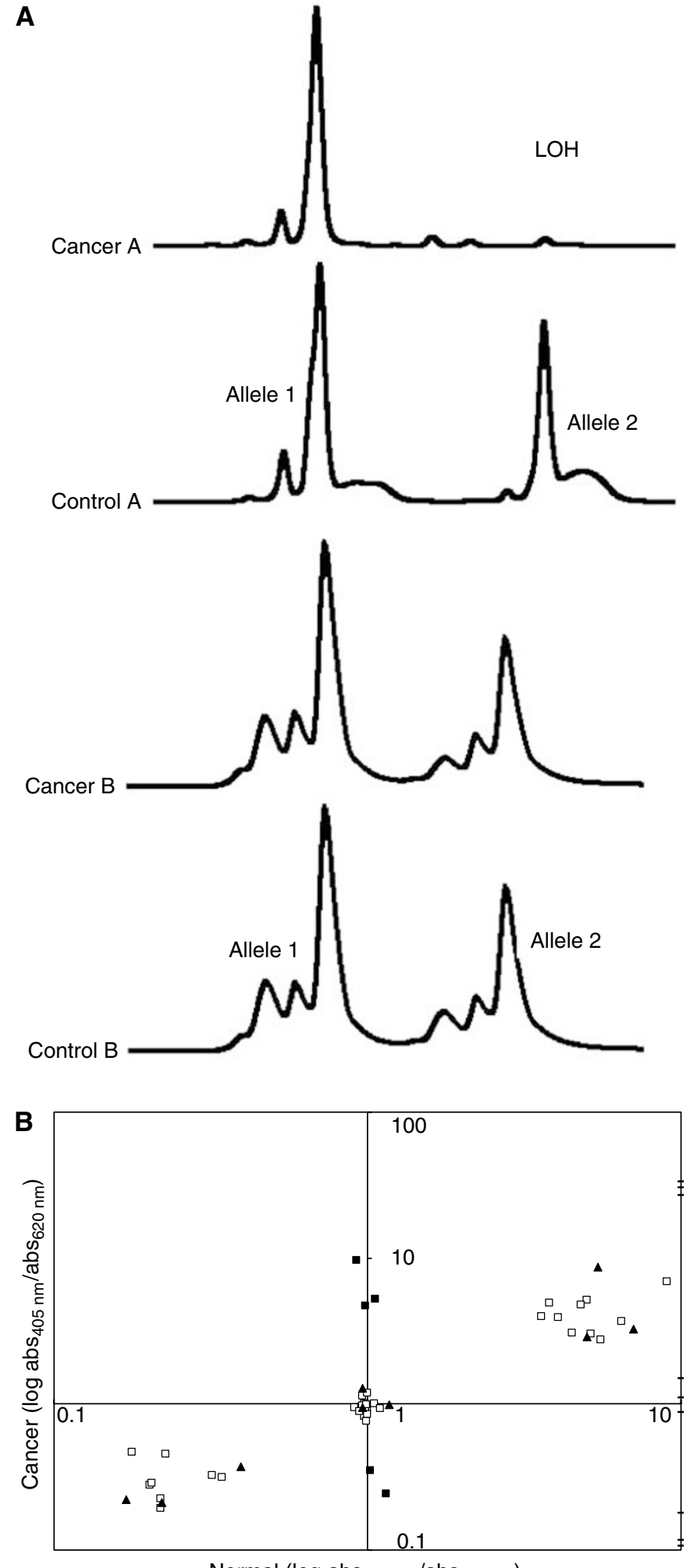

Normal (log abs 405 mm $\left./ a b_{620 ~ n m}\right)$

Figure 2 (A) Loss of heterozygosity in cancer A but not in cancer B at the D3SI300 locus as detected by microsatellite analysis. (B) Loss of heterozygosity at the rs 722070 locus by SNP analysis. Results of a representative experiment involving 33 test samples. $\square$, Homozygous cases or heterozygous cases showing no $\mathrm{LOH}$. $\mathbf{\square}$, Five heterozygous cases showing $\mathrm{LOH}$ in the cancer, confirmed by repeat testing. - Positive controls for allele I, allele 2 and alleles I + 2 (supplied by the manufacturer) tested in triplicate. $\boldsymbol{\Lambda}$. Nine control samples previously tested and confirmed to be homozygous or heterozygous at this locus. 
Loss of heterozygosity in $3 p$ Figure 2 shows representative $\mathrm{LOH}$ profiles obtained by microsatellite analysis (Figure 2A) and SNP analysis (Figure 2B). Loss of heterozygosity in $3 p$ can occur over the entire length of the chromosome (Table 1) and the occurrence of $\mathrm{LOH}$ anywhere within $3 \mathrm{p}$ was associated with increasingly poor histological differentiation and with increased depth of invasion (Table 3a). Overall, LOH was found in $57 \%$ cancers and the number of loci lost ranged from 1 to 11 (Figure 3). No significant association was found between LOH in the MLH1 mismatch repair gene and markers of cancer progression.

FHIT protein expression Genomic instability in the FHIT gene was associated with loss of FHIT expression in a total of two loci out of seven examined, both located within in intron 5 (Table $3 b$ ). The loss of FHIT protein expression was not correlated with any of the markers of cancer progression studied.

\section{Evaluation of HR HPV, 3p LOH and FHIT expression in CIN1 and CIN1* lesions}

A total of 29 CIN1 lesions were positive for HR HPV, of which 10 contained HPV16. The incidences of HPV16, HR HPV as a group and $\mathrm{LOH}$ in and close to FHIT intron 5 were not significantly different in the two CIN1 categories, but the incidence of abnormal
FHIT protein expression was significantly higher in $\mathrm{CIN}^{*}$ (38 vs 10\%) (Tables 4 and 5).

\section{DISCUSSION}

In all, 93\% of cervical cancers contained HR HPV. HPV16 was the most common and was detected in $61 \%$ cancers overall and $71 \%$ of squamous carcinomas. Although HR HPV is known to be pivotal in the development of cervical cancer, its role in cancer progression as assessed here for HPV16 against histological markers was found to be limited to an association with vascular involvement. HPV16 occurred more frequently in moderately differentiated cancers and did not show any preference for adenosquamous carcinoma, a histological type which is usually poorly differentiated and has a lower 5-year survival rate (Davy et al, 2003; Farley et al, 2003). In contrast, LOH in 3p was found to be associated with poor differentiation, increased depth of invasion and, when the LOH occurred in FHIT intron 3 with lymph node involvement or in FHIT intron 5 with abnormal FHIT protein expression (Table $3 \mathrm{~b}$ ). Abnormal FHIT protein expression was not associated with any of the markers of cancer progression examined. This suggests that chromosomal instability alone may be an underlying factor in the histological manifestation of markers of cancer progression observed.

Table 3 Significant associations between LOH in 3p and markers of cancer progression, HR HPV and FHIT protein expression in 83 cancers: (a) Allelic loss in any region of 3p; (b) allelic loss at specific $3 p$ loci for cancers informative at that locus calculated

\begin{tabular}{|c|c|c|c|c|c|c|c|c|}
\hline LOH site & Risk markers & \multicolumn{2}{|c|}{ Total } & \multicolumn{2}{|c|}{ Risk marker positive } & \multicolumn{3}{|c|}{ Statistical analysis } \\
\hline \multirow{3}{*}{ Anywhere on 3p } & - moderate & 36 & 47 & 19 & 23 & & 7.26 & \\
\hline & - poor & 36 & 47 & 11 & 23 & & 12.55 & \\
\hline & & & & & & \multicolumn{3}{|l|}{$P$-trend $=0.018$} \\
\hline FHIT intron 3 & Lympn node involvement & 28 & 10 & 5 & 8 & $2 P<0.001$ & 18.400 & $2.382-206.044$ \\
\hline FHIT intron 5 (SNP) & Depth $\geqslant 10 \mathrm{~mm}$ & 28 & 10 & 18 & 10 & $2 P=0.038$ & & $1.305-^{a}$ \\
\hline FHIT intron 5 (MS) & Depth $\geqslant 10 \mathrm{~mm}$ & 54 & 20 & 31 & 20 & $2 P<0.001$ & a & $3.707-{ }^{\mathrm{a}}$ \\
\hline & Abnormal FHIT protein & 54 & 20 & 25 & 16 & $2 P=0.017$ & 4.640 & $1.247-21.169$ \\
\hline
\end{tabular}

${ }^{\mathrm{a} C}$ Cannot be calculated.

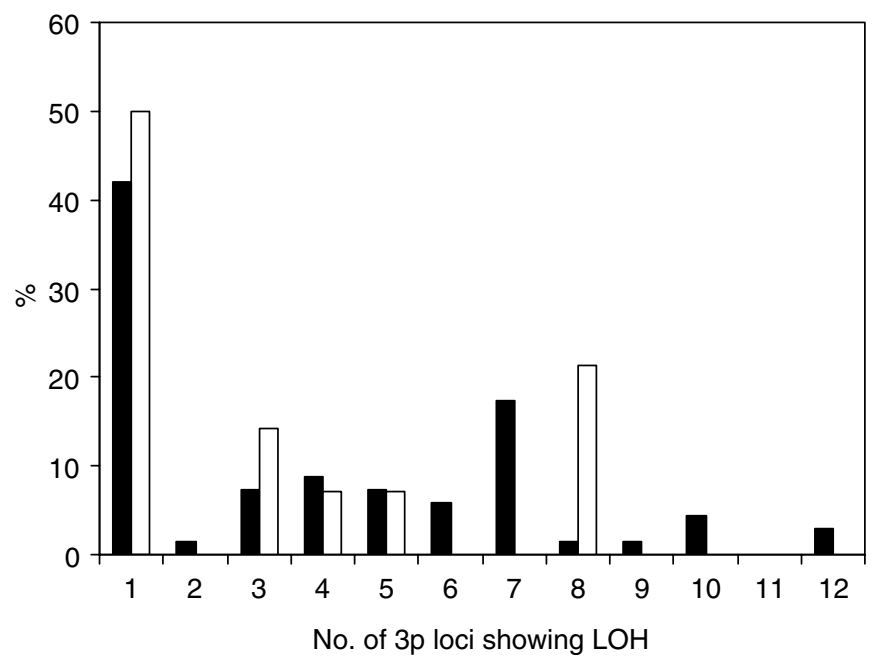

Figure 3 The number of $3 p$ loci with $\mathrm{LOH}$ in individual cancers. Group A (including HPVI6) $\square$ HPVI8.
Table 4 Cancer prognostic markers in CINI and CINI** lesions

\begin{tabular}{lccc}
\hline Parameters & $\begin{array}{c}\text { CIN I lesions } \\
(\mathbf{n}=\mathbf{5 0 )}\end{array}$ & $\begin{array}{c}\text { CINI* lesions } \\
(\mathbf{n}=\mathbf{2 4 )}\end{array}$ & $\mathbf{2 p}$ \\
\hline HR HPV & 5 & 5 & 0.277 \\
I6 & 4 & 2 & 1.000 \\
I8 & 10 & 3 & 0.528 \\
Others & 31 & 14 & 0.803 \\
None & & & \\
D3SI300 locus & 5 & 4 & 0.216 \\
LOH & 35 & 10 & \\
HET/no LOH & & & \\
D3SI582 locus & 2 & 3 & 0.314 \\
LOH & 39 & 16 & \\
HET/no LOH & & & \\
FHIT protein & & 15 & 0.009 \\
Present & & & \\
Absent or reduced & 5 & 9 & \\
\hline
\end{tabular}

${ }^{a}$ Other types detected were HPV 6, 11, 18, 30, 31, 45, 52, 53, 56, 58, 66 and 67. 
Table 5 Association between co-existing lesion grades and FHIT or PCNA protein status of CIN and CINI* lesions

\begin{tabular}{|c|c|c|c|c|c|c|c|}
\hline \multirow{2}{*}{ Co-existing lesion } & \multirow{2}{*}{ Total } & \multicolumn{6}{|c|}{ CINI lesion status } \\
\hline & & \multicolumn{3}{|c|}{ FHIT } & \multicolumn{3}{|c|}{ PCNA } \\
\hline None & 50 & 5 & & 1.00 & 35 & & 1.00 \\
\hline $\mathrm{CINI} / \mathrm{CIN} 2$ & 3 & 1 & & 4.50 & 2 & & 0.86 \\
\hline CIN3 & 9 & 3 & 0.010 & 4.50 & 8 & 0.861 & 3.43 \\
\hline
\end{tabular}

It is of current interest to find markers which can identify those CIN1 lesions which are likely to progress to more severe grades, and HR HPV and the FHIT gene are two likely candidates. In this study, we considered that $\mathrm{CIN} 1^{*}$ lesions should indicate a greater potential for progression because there is good evidence to suggest that co-existing lesions, even when topographically distinct, could have a common origin and could be under the influence of the same 'field' effect (Larson et al, 1977; Park et al, 1998) and abnormal FHIT protein expression has been found to occur more frequently in CIN $2 / 3$ lesions co-existing with cancer (Connolly et al, 2000). Our results show that CIN1 and $\mathrm{CIN} 1^{\star}$ lesions have a similar incidence of HPV16 or other HR HPV (Table 4) so that the detection of HR HPV per se may not be sufficient to predict progression of CIN1. Interestingly, the incidence of abnormal FHIT protein expression in $\mathrm{CIN}^{*}$ is similar to that reported for CIN2/3 lesions (Birrer et al, 1999; Connolly et al, 2000; Terry et al,

\section{REFERENCES}

Acevedo CM, Henriquez M, Emmert-Buck MR, Chuaqui RF (2002) Loss of heterozygosity on chromosome arms $3 \mathrm{p}$ and $6 \mathrm{q}$ in microdissected adenocarcinomas of the uterine cervix and adenocarcinoma in situ. Cancer 94: 793 - 802

Birrer MJ, Hendricks D, Farley J, Sundborg MJ, Bonome T, Walts MJ, Geradts J (1999) Abnormal Fhit expression in malignant and premalignant lesions of the cervix. Cancer Res 59: 5270-5274

Borysiewicz LK, Fiander A, Nimako M, Man S, Wilkinson GW, Westmoreland D, Evans AS, Adams M, Stacey SN, Boursnell ME, Rutherford E, Hickling JK, Inglis SC (1996) A recombinant vaccinia virus encoding human papillomavirus types 16 and 18, E6 and E7 proteins as immunotherapy for cervical cancer. Lancet 347: 1523-1527

Chung TKH, Cheung TH, Lo WK, Yu MY, Hampton GM, Wong HKT, Wong YF (2000) Loss of heterozygosity at the short arm of chromosome 3 in microdissected cervical intraepithelial neoplasia. Cancer Lett 154: $189-194$

Connolly DC, Greenspan DL, Wu R, Ren X, Dunn RL, Shah KV, Jones RW, Bosch FX, Munoz N, Cho KR (2000) The loss of Fhit expression in invasive cervical carcinomas and intraepithelial lesions associated with invasive disease. Clin Cancer Res 6: 3505-3510

Corbin S, Neilly ME, Espinosa III R, Davis EM, McKeithan TW, Le Beau MM (2002) Identification of unstable sequences within the common fragile site at 3 p14.2: implications for the mechanism of deletions within fragile histidine triad gene/common fragile site at 3 p14.2 in tumors. Cancer Res 62: $3477-3484$

Cuzick J, Terry G, Ho L, Monaghan J, Lopes A, Clarkson P, Ducan I (2000) Association between high-risk HPV types, HLA DRB1* and DQB1* alleles and cervical cancer in British women. Br J Cancer 82: $1348-1352$

Davy MLJ, Dodd TJ, Luke CG, Roder DM (2003) Cervical cancer: effect of glandular cell type on prognosis, treatment, and survival. Obstet Gynecol 101: $38-45$

Druck T, Kastury K, Hadaczek P, Podolski J, Toloczko A, Sikorski A, Ohta M, LaForgia S, Lasota J, McCue P (1995) Loss of heterozygosity at the
2002 ) and it was also correlated with the severity of the initially coexisting lesion grades (Table 5). If these findings are confirmed by a larger study, abnormal expression of FHIT protein in either biopsies (as in this study) or in cervical smears (Vecchione et al, 2001) could represent an additional marker for progressive potential in CIN1 lesions. Replacement therapy for the FHIT protein might also be effective in preventing the progression of CIN1 to higher grade lesions.

\section{ACKNOWLEDGEMENTS}

We thank Ms Mary Walker (Department of Cyto-Histopathology, Gateshead Health NHS Trust, Queen Elizabeth Hospital) for preparing the paraffin sections and the pathology reports. familial RCC $t(3 ; 8)$ locus in most clear cell renal carcinomas. Cancer Res 55: $5348-5353$

Dumon KR, Ishii H, Vecchione A, Trapasso F, Baldassarre G, Chakrani F, Druck T, Rosato EF, Williams NN, Baffa R, During MJ, Huebner K, Croce CM (2001) Fragile histidine triad expression delays tumor development and induces apoptosis in human pancreatic cancer. Cancer Res 61: $4827-4836$

Farley JH, Hickey KW, Carlson JW, Rose GS, Kost ER, Harrison TA (2003) Adenosquamous histology predicts a poor outcome for patients with advanced-stage, but not early-stage, cervical carcinoma. Cancer 97: $2196-2202$

Glover TW, Stein CK (1988) Chromosome breakage and recombination at fragile sites. Am J Hum Genet 43: 265-273

Guo Z, Wu F, Asplund A, Hu X, Mazurenko N, Kisseljov F, Pontén J, Wilander E (2001) Analysis of intratumoral heterogeneity of chromosome $3 p$ deletions and genetic evidence of polyclonal origin of cervical squamous carcinoma. Mod Pathol 14: 54-61

Hibi K, Takahashi T, Yamakawa K, Ueda R, Sekido Y, Ariyoshi Y, Suyama M, Takagi H, Nakamura Y, Takahashi T (1992) Three distinct regions involved in 3p deletions in human lung cancer. Oncogene 7: 445-449

Ji L, Fang B, Yen N, Fong K, Minna JD, Roth JA (1999) Induction of apoptosis and inhibition of tumorigenicity and tumor growth by adenovirus vector-mediated fragile histidine triad (FHIT) gene overexpression. Cancer Res 59: 3333-3339

Kastury K, Baffa R, Druck T, Ohta M, Cotticelli MG, Inoue H, Negrini M, Rugge M, Huang D, Croce CM, Palazzo J, Huebner K (1996) Potential gastrointestinal tumor suppressor locus at the 3p14.2 FRA3B site identified by homozygous deletions in tumor cell lines. Cancer Res 56: $978-983$

Kleter B, Doorn LJ, Schegget J, Schrauwen L, Krimpen K, Burger M, Harmsel B, Quint W (1998) Novel short-fragment PCR assay for highly sensitive broad-spectrum detection of anogenital human papillomaviruses. Am J Pathol 153: 1731 - 1739 
Larson AA, Liao SY, Stanbridge EJ, Cavenee WK, Hampton GM (1977) Genetic alterations accumulate during cervical tumorigenesis and indicate a common origin for multifocal lesions. Cancer Res 57: $4171-4176$

Li J, Yen C, Liaw D, Podsypanina K, Bose S, Wang SI, Puc J, Miliaresis C, Rodgers L, McCombie R, Bigner SH, Giovanella BC, Ittmann M, Tycko B, Hibshoosh H, Wigler MH, Parsons R (1997) PTEN, a putative protein tyrosine phosphatase gene mutated in human brain, breast, and prostate cancer. Science 275: $1943-1947$

Munoz N, Bosch FX, de Sanjose S, Herrero R, Castellsague X, Shah KV, Snijders PJ, Meijer CJ, International Agency for Research on Cancer Multicenter Cervical Cancer Study Group (2003) Epidemiologic classification of human papillomavirus types associated with cervical cancer. $N$ Engl J Med 348: 518-527

Naylor SL, Johnson BE, Minna JD, Sakaguchi AY (1987) Loss of heterozygosity of chromosome $3 \mathrm{p}$ markers in small cell lung cancer. Nature 329: $451-454$

Park J, Sun D, Genest DR, Trivijitsilp P, Suh I, Crum CP (1998) Coexistence of low and high grade squamous intraepithelial lesions of the cervix: morphologic progression or multiple papillomaviruses? J Gynecol Oncol 70: $386-391$

Roz L, Gramegna M, Ishii H, Croce CM, Sozzi G (2002) Restoration of fragile histidine thriad (FHIT) expression induces apoptosis and suppresses tumorigenicity in lung and cervical cancer cell lines. Proc Natl Acad Sci USA 99: 3615-3620

Sard L, Accomero P, Tornielli S, Delia D, Bunone G, Campiglio M, Colombo MP, Gramegna M, Croce CM, Pierotti MA, Sozzi G (1999) The tumor- suppressor gene FHIT is involved in the regulation of apoptosis and in cell cycle control. Proc Natl Acad Sci USA 96: 8489-8492

Schantz SP, Huang Q, Shah K, Murty VVVS, Hsu TC, Yu Guopei G, Andersen PE, Huvos AG, Chaganti RSK (2000) Mutagen sensitivity and environmental exposures as contributing causes of chromosome $3 \mathrm{p}$ losses in head and neck cancers. Carcinogenesis 21: 1239-1246

Terry G, Ho L, Londesborough P, Cuzick J (2002) Abnormal FHIT expression profiles in cervical intraepithelial neoplastic (CIN) lesions. $\mathrm{Br}$ J Cancer 86: $376-381$

Thorland EC, Myers SL, Persing DH, Sarkar G, McGovern RM, Gostout BS, Smith DI (2000) Human papillomavirus type 16 integrations in cervical tumors frequently occur in common fragile sites. Cancer Res 60: $5916-5921$

Vecchione A, Zanesi N, Trombetta G, French D, Visca P, Pisani T, Botti C, Vecchione A, Croce CM, Mancini R (2001) Cervical dysplasia, ploidy and human papillomavirus status correlate with loss of FHIT expression. Clin Cancer Res 7: $1306-1312$

Wistuba II, Montellano FD, Milchgrub S, Virmani AK, Behrens C, Chen H, Ahmadian M, Nowak JA, Muller C, Minna JD, Gazdar AF (1997) Deletions of chromosome $3 p$ are frequent and early events in the pathogenesis of uterine cervical carcinoma. Cancer Res 57: $3154-3158$

Ylitalo N, Josefsson A, Melbye M, Sorensen P, Frisch M, Andersen PK, Sparen P, Gustafsson M, Magnusson P, Ponten J, Gyllensten U, Adami H (2000) A prospective study showing long-term infection with human papillomavirus 16 before the development of cervical carcinoma in situ. Cancer Res 60: 6027-6032 